\title{
SATISFAÇÃO, CONFLITOS E ENGAJAMENTO NO TRABALHO PARA PROFESSORES DO ENSINO MÉDIO
}

\author{
SATISFACTION, CONFLICTS AND ENGAGEMENT AT WORK FOR HIGH SCHOOL TEACHERS
}

Recebido em 28.08.2017. Aprovado em 18.10.2017

Avaliado pelo sistema double blind review

DOI: http://dx.doi.org/10.12712/rpca.v11i4.1004

\section{Jandir Pauli}

FACULDADE IMED, Passo Fundo/RS, BRASIL

jandir@imed.edu.br

\section{Manueli Tomasi}

FACULDADE IMED, Passo Fundo/RS, BRASIL

manuelitomasi5@gmail.com

\section{Shalimar Gallon}

FACULDADE IMED, Passo Fundo/RS, BRASIL

shalimar.gallon@imed.edu.br

\section{Elenise Coelho}

FACULDADE IMED, Passo Fundo/RS, BRASIL

elenise.ac@gmail.com

\begin{abstract}
Resumo
O presente artigo tem como objetivo descrever a relação entre conflitos intragrupais, engajamento e satisfação com o trabalho para professores da rede pública do Ensino Médio. Trata-se de uma pesquisa descritiva e quantitativa de corte transversal com a aplicação de 201 questionários a professores de dez escolas públicas. As análises mostraram que os conflitos de ordem afetiva influenciaram diretamente na percepção de Satisfação no Trabalho. Além disto, a satisfação com a natureza do trabalho está diretamente relacionada com o engajamento e esta relação é moderada pela percepção de conflitos intragrupais. Os resultados encontrados sugerem que, para os professores, os conflitos são importantes vetores do engajamento, enfatizando a necessidade de promover vivências positivas nas atividades laborais e preservando a natureza do trabalho docente.
\end{abstract}

Palavras-chave: Satisfação no trabalho. Engajamento. Conflitos intragrupais. Professores.

\begin{abstract}
This article aims to describe the relationship between intragroup conflicts, engagement and job satisfaction for teachers of the public high school. This is a quantitative descriptive cross-sectional survey with the application of 201 questionnaires to teachers from ten public schools. The analyzes showed that affective conflicts directly influenced the perception of Work Satisfaction. In addition, satisfaction with the nature of work is directly related to engagement and this relationship is moderated by the perception of intragroup conflict. The results suggest that for teachers, conflicts are important vectors of engagement, emphasizing the need to promote positive experiences in work activities in schools, preserving the nature of teaching work.
\end{abstract}

Keywords: Satisfaction at work. Engagement. Intragroup conflicts. Teachers. 


\section{Introdução}

Nas últimas décadas, o tema da relação entre trabalho e saúde psíquica do trabalhador tem sido amplamente explorado (DEJOURS, 2004; DO CARMO; GUIMARÃES; CAEIRO, 2017; ROSSI, 2011). O trabalho prazeroso propicia ao trabalhador a percepção de reconhecimento, satisfação, abertura para cooperação, autonomia, melhora do clima organizacional, além de influenciar positivamente nos hábitos de vida dos sujeitos (LOCKE, 1969). Em contrapartida, a má organização de trabalho pode gerar sobrecarga, conflito nas relações e surgimento de riscos psicossociais como, medo e insegurança, podendo causar insatisfação e diminuição do engajamento dos trabalhadores para executar as atividades laborais (MENDES, 2007a; MENDES, 2007b).

O trabalho docente apresenta algumas particularidades ligadas ao reconhecimento social da profissão, uma vez que assume a missão de formar cidadãos críticos que sejam capazes de intervir no contexto social do qual fazem parte (FRAGA, 2007). Entretanto, o atual cenário educacional tem sido marcado por um constante descontentamento destes profissionais com determinados aspectos do seu trabalho. Dentre os quais, pode-se citar a sobrecarga de tarefas, a falta de reconhecimento, a remuneração baixa e a falta de investimentos na educação (SINOTT et al., 2014). Entre as estratégias de enfrentamento destas dificuldades, fatores como a boa convivência com os colegas no ambiente pedagógico e a comunicação organizacional tem sido apresentadas como fontes de satisfação (NASCIMENTO; SIMÕES, 2011). Segundo Capistrano e Cirotto (2014), os professores que demonstram satisfação no ambiente de trabalho são os que mantém bons relacionamentos e se envolvem em tarefas junto com a coordenação e a equipe escolar. Os mesmos autores relataram que a recompensa financeira pelo desempenho do professor não tem um impacto significativo na satisfação com a profissão, quando comparado a outros fatores como, possibilidade de avanço na carreira e o reconhecimento público do diretor e dos colegas.

$\mathrm{Na}$ literatura brasileira e internacional encontra-se uma variedade de estudos com professores que atuam no ensino médio, elegendo os aspectos psicológicos e físicos da qualidade de vida, satisfação e bem-estar no trabalho, como temáticas centrais para compreender as possíveis práticas organizacionais que podem potencializar um ambiente de trabalho mais estável e prazeroso para os trabalhadores (AGAPITO; FILHO; SIQUEIRA, 2015; CAPISTRANO; CIROTTO, 2014; JANKE; NITSCHE; DICKHÄUSER, 2015; OLIVEIRA et al., 2016).

Deste modo, a singularidade deste trabalho está em localizar a discussão em um extrato profissional específico - professores do ensino médio da rede pública - para descrever a relação entre três variáveis inerentes ao ambiente acadêmico: satisfação no trabalho, conflitos e engajamento no trabalho. Assim, estudar a satisfação e engajamento a partir das relações intragrupais pode contribuir para preencher gaps na pesquisa sobre o trabalho docente, permitindo novos conhecimentos sobre as características de trabalho dentro das escolas, além de possíveis intervenções que estas organizações podem realizar, possibilitando o alinhamento das expectativas dos professores com as da escola ou ambiente em que atuam. Com esta base, o objetivo deste estudo é descrever a relação entre conflitos intragrupais, satisfação, e engajamento no trabalho de professores do Ensino Médio da rede pública.

Foi realizada uma pesquisa de tipo survey, quantitativa, descritiva e de corte transversal com a utilização de um questionário construído a partir de três escalas: a Escala de Satisfação do Trabalho (EST) - validada por Siqueira (1995) -, a Escala de Engajamento (EEGT) - validada por Siqueira et al. (2011) - e a Escala de Conflitos Intragrupais (ECI) - validada por Martins, Guimarães e Oliveira (2006). Os questionários foram aplicados a 201 professores atuantes em escolas da rede pública estadual de ensino médio na região norte do estado do Rio Grande do Sul (RS). As escalas utilizadas foram escolhidas pela sua confiabilidade comprovada, por terem sido desenvolvidas no contexto brasileiro e por possuírem as dimensões necessárias para a investigação do modelo de análise.

Este artigo foi construído em três partes. Na primeira seção foi desenvolvida a fundamentação teórica; na segunda seção descreve-se a metodologia da pesquisa; e, por fim, na terceira seção apresentam-se os resultados e a análise dos dados para discussão dos resultados.

\section{Conflitos Intragrupais, Satisfação e Engajamento no Trabalho}

O referencial teórico está estruturado em três subseções que correspondem a definição e os pressupostos 
teóricos das variáveis em estudo, a saber: conflitos intragrupais, satisfação e engajamento no trabalho.

\section{Conflitos intragrupais}

A demanda pelas inovações e as mudanças constantes que afetam o cenário organizacional, tornam necessária à compreensão das consequências e repercussões dos conflitos existentes nas organizações (GUIMARÃES, 2007). O assunto tem despertado o interesse de gestores e pesquisadores do comportamento organizacional, pois é por meio da ação dos trabalhadores que os objetivos organizacionais são alcançados (DA SILVA; DOS SANTOS; DE SAMPAIO, 2016; NASCIMENTO; SIMÕES, 2010). Entretanto, as organizações reúnem pessoas que diferem nas suas iniciativas, formas de pensar e de agir, criando a necessidade de conciliar objetivos e interesses particulares, em torno de um propósito organizacional comum. Neste contexto, torna-se natural a presença de conflitos (NASCIMENTO; SIMÕES, 2010).

O conflito intragrupal evidenciado neste estudo refere-se aos conflitos vivenciados entre os membros de um mesmo grupo em uma organização (JEHN, 1994). Os primeiros pesquisadores a descrever e classificar esta terminologia foram Guetzkow e Gyr (1954), ao referirem-se as equipes e processos decisórios, quando destacaram dois tipos de conflitos possíveis de emergir em um grupo de trabalho: os conflitos voltados para as tarefas que o grupo está desempenhando; e os conflitos baseados nas relações interpessoais do grupo, nomeando-os, respectivamente, como conflito substantivo e conflito afetivo. Considerando os dois tipos de conflitos, de relacionamento e de tarefas, Jehn (1994) identificou que o conflito de relacionamento incluiria indicadores emocionais e afetivos como atritos, tensão ou raiva entre os membros do grupo, enquanto o conflito de tarefas envolveria indicadores cognitivos, como diferentes pontos de vista e opiniões relacionados ao planejamento e execução das atividades do grupo.

Essa visão bidimensional do conflito também foi adotada por Martins, Guimarães e Oliveira (2006) ao ressaltarem que os conflitos de relacionamento não são focados nas tarefas, pois tem sua origem em diferenças de preferências individuais e valores pessoais. No entanto, podem se originar por discordâncias entre os membros do grupo no planejamento e execução de atividades, contribuindo para o declínio da satisfação com o trabalho, uma vez que o conflito de relacionamento medeia completa ou totalmente a relação entre o conflito de tarefa e as respostas afetivas do grupo. Além disso, o conflito de tarefa, por vezes, pode ser visto de forma positiva, tendo em vista que eleva a eficácia do grupo através das discussões acerca do trabalho a ser executado. O conflito de relacionamento não só prejudica o grupo no que se refere às questões afetivas, como também pode gerar consequências negativas em torno da tarefa a ser realizada (MARTINS; GUIMARÃES; OLIVEIRA, 2006; NASCIMENTO; SIMÕES, 2011).

Estudos correlatos confirmam o caráter disfuncional do conflito de relacionamento nos grupos, como os resultados da pesquisa de Guimarães e Martins (2008) que objetivou testar a capacidade de predição das bases de poder do supervisor e dos conflitos intragrupais percebidos na equipe de trabalho sobre o comprometimento organizacional e afetivo com a equipe. $\mathrm{O}$ estudo mostra que, o conflito intragrupal de relacionamento é um preditor negativo de ambos os focos de comprometimento afetivo, tanto no âmbito grupal, quanto no âmbito organizacional. Além disso, o estudo também demonstrou que o tipo de conflito de tarefa não foi preditor significante das variáveis pesquisadas (GUIMARÃES; MARTINS, 2008).

Por outro lado, Martins e Tavares (2013) ressaltam que ambos os conflitos - socioafetivos e de tarefas estão presentes nas relações de trabalho e coexistem entre si, sugerindo que um conflito que se origina nas tarefas desempenhadas pelo grupo, pode vir a ser interpretado no plano socioafetivo. Em contrapartida, Dimas, Lourenço e Miguéz (2007) destacam que, o conflito, em perspectivas mais recentes, pode apresentar potencialidades ao nível da inovação e da criatividade das equipes de trabalho.

Entretanto, no que se refere a existência de conflitos no âmbito escolar, Guerreiro et al (2016) mostraram que o fato de cuidar de duas turmas ao mesmo tempo, devido à falta de professores, por exemplo, pode ser um fator desencadeante de conflito entre o grupo. Esse fator desencadeia o sentimento de insatisfação com o trabalho e, consequentemente, a falta de engajamento nas tarefas (GUERREIRO et al., 2016). Nesta mesma linha, a pesquisa de Carraro e Dos Santos (2011), realizada com professores de uma escola pública, constatou que os professores tinham muitos problemas de relacionamento entre colegas e na execução de tarefas. Outro aspecto importante a 
ser destacado, é que, o fato de passar por momentos negativos no trabalho, como situações conflitivas, tensões e sobrecarga de tarefas, pode influenciar diretamente na quantidade de afastamentos e abandonos da carreira (GUERREIRO et al., 2016). Desta forma, compreender os conflitos intragrupais existentes nas escolas, possibilita traçar estratégias diferenciadas para alcançar os objetivos almejados, bem como mapear os fatores envolvidos na relação indivíduo-organização (MARTINS; TAVARES, 2013; NASCIMENTO; SIMÕES, 2010; SIQUEIRA, 2008).

\section{Satisfação no trabalho}

A satisfação caracteriza-se por um estado emocional do trabalhador, não só em seu ambiente de trabalho, mas também por um contentamento em sua vida pessoal. Esse conceito foi estudado por Locke (1969) como causa de determinados comportamentos, tais como produtividade e desempenho. $\mathrm{O}$ autor também define a satisfação no trabalho como o resultado da avaliação que o indivíduo tem sobre o seu trabalho, ou a realização de seus valores por meio dessa atividade, sendo uma emoção positiva de bem-estar (LOCKE, 1969).

Nesta perspectiva, a realização de uma tarefa não se dá apenas pela execução de ações físicas, mas sim, por existir evidências de recompensas, tanto materiais quanto pessoais. Desta forma, o fato de poder dominar uma atividade e ser reconhecido positivamente por procedê-la, faz com que haja um grau maior de motivação na concretização da mesma, gerando assim um sentimento de autorrealização e crescimento pessoal, e principalmente, de satisfação com o trabalho executado.

A satisfação com o trabalho pode ser descrita como de origem afetiva ou cognitiva, já que é definida como uma situação positiva e emocional de prazer que foi obtida após experiências de trabalho, tendo então um constructo mais afetivo. Neste sentido, o trabalho deve estar ligado com a vida e ter significados, a fim de que os indivíduos consigam construir relacionamentos, realizar planos, e projetos (SIQUEIRA; GOMIDE JR., 2004; MACHADO et al., 2014).

Paraumbom funcionamento organizacional,éessencial que os trabalhadores estejam satisfeitos (MURAD; ZAYED; MUKUL, 2013). Essa satisfação vai além do aspecto financeiro, pois envolve um conjunto de componentes que podem estar relacionados à: satisfação com os colegas, salário, chefia, natureza do trabalho e promoções (MURAD; ZAYED; MUKUL, 2013). As experiências prazerosas no trabalho levam a um estado emocional agradável ou positivo dos sujeitos, gerando engajamento dos trabalhadores e podendo obter melhores resultados em termos de criatividade e comprometimento (LOCKE, 1976). Para tanto, estudar a satisfação compreende analisar os retornos ofertados no ambiente de trabalho salários, promoções e convivência com os colegas e as chefias - que propiciam ao trabalhador sentimentos de prazer e de gratificação (LOCKE, 1969; MELO; BARBOSA; SOUZA, 2011; SIQUEIRA, 2008).

Em estudos que abordam a temática, para Siqueira (2003) e Siqueira (2005), as pesquisas sobre a satisfação no trabalho demonstraram pouca influência de fatores sociodemográficos (sexo, idade, estado civil), ambiente físico (ruídos e iluminação) e estrutura das organizações (matricial ou funcional), nos níveis de satisfação ou insatisfação. Em contrapartida, existe um maior impacto nas questões relacionadas a valores organizacionais, percepção de justiça, percepções de suporte e de reciprocidade, que são estabelecidas nas relações sociais e econômicas entre empregados e organização (SIQUEIRA, 2003; SIQUEIRA, 2005).

O estudo de Farias et al (2015) com professores de educação física da rede pública mostrou que existem outros fatores que no decorrer da carreira tornamse fundamentais para satisfação profissional. Esses fatores são inerentes aos aspectos pedagógicos e relacionais com os alunos e os pares (professores e demais profissionais da escola) e incidem na satisfação no trabalho. O bom relacionamento também está relacionado com a permanência do professor na carreira docente (FARIAS et al., 2015).

Frente aisso, existe uma preocupação dos pesquisadores que recai sobre a construção e a validação de medidas de satisfação no trabalho. No contexto brasileiro, os autores têm se dedicado a construir medidas que possam mensurar tal constructo (COELHO; FAIAD, 2012; MARTINS; SANTOS, 2006; CALDAS et al., 2013). Exemplo disso é a pesquisa realizada por Rueda et al. (2010) que teve como objetivo a verificação de evidências para validar a escala de suporte laboral, aplicada em diferentes enfoques. Ademais, a pesquisa de Neves, Para tanto, a satisfação é um conceito que vem sendo estudado em diferentes áreas, inclusive, na Psicologia e Administração. $\mathrm{Na}$ literatura, há diferentes abordagens sobre a satisfação, visto que é 
um fenômeno complexo e de difícil definição, além de abranger diversos âmbitos da vida dos sujeitos (MARTINEZ; PARAGUAY, 2003). Assim, no presente estudo, entende-se que a satisfação está relacionada a um melhor vínculo afetivo entre o indivíduo e o seu trabalho, e é considerada a principal fonte de reconhecimento, realização, desenvolvimento, saúde e bem-estar dos sujeitos (CESAR, 2010; DE ANDRADE; MIRANDA; JARDIM, 2011).

\section{Engajamento}

Definido como um fenômeno que ocorre no ambiente organizacional, o engajamento no trabalho é geralmente associado ao bem-estar físico e mental dos trabalhadores, influenciando tanto no vigor e energia, quanto na absorção e concentração no trabalho (BAKKER; DEMEROUTI, 2008). Além disso, estar engajado é um fator motivacional positivo relacionado ao bem-estar ou a uma satisfação caracterizada por um alto nível de energia e uma forte identificação com o próprio trabalho (BAKKER; DEMEROUTI; LIEKE, 2012; SIQUEIRA et al., 2014).

Neste contexto, Bakker e Laiter (2010) e Schaufeli e Bakker (2009) estudaram os aspectos positivos relacionados ao ambiente de trabalho. Essas pesquisas definiram o engajamento no trabalho por alguns sentimentos, sendo que um deles era caracterizado pelo vigor e absorção ao realizar as tarefas, aumentando o sentimento de satisfação e realização com o trabalho. Para tanto, o vigor foi caracterizado pelos altos níveis de energia e persistência, mesmo quando ocorrem dificuldades no ambiente de trabalho, enquanto que a absorção associa-se ao quanto o indivíduo se mantém concentrado e dedicado ao próprio trabalho.

Sob este aspecto os estudos de Hakanen, Schaufeli e Ahola (2008) e Bakker e Leiter (2010) observaram a importância de trabalhadores engajados no ambiente de trabalho, visto que indivíduos mais engajados tem a capacidade de conduzir a inovação aos recursos no trabalho. Além disso, também encontraram construções de engajamento no trabalho associadas a um resultado positivo - dedicação e compromisso -, assim como o engajamento no trabalho sem a intenção de rotatividade. Já o estudo realizado por Caldas et al. (2013) com 71 docentes atuantes no ensino à distância de uma universidade privada brasileira, verificou uma significativa e positiva correlação entre satisfação e engajamento no trabalho, uma vez que, a boa relação entre os trabalhadores, chefias e seus pares, pode influenciar na predisposição do indivíduo em realizar suas tarefas com maior absorção.

Nesta perspectiva, as pessoas engajadas são aquelas que colocam mais esforços no seu trabalho, porque além de se identificarem com o trabalho exercido, elas são capazes de produzir resultados positivos para o seu próprio desenvolvimento e crescimento, bem como trazem resultados positivos para a organização (SIQUEIRA et al., 2014). Assim, compreender os aspectos positivos em uma organização, e o que possibilita os trabalhadores se sentirem satisfeitos, envolvidos e comprometidos com suas tarefas, tornase fundamental para que as organizações saibam como estimular seus trabalhadores a alcançarem os objetivos organizacionais. Deste modo, a temática do engajamento no trabalho apresenta aspectos essenciais e significativos a serem compreendidos, visando à saúde física e psíquica dos trabalhadores (CAVALCANTE, 2013).

A partir do exposto, o presente estudo propõe-se a testar as seguintes hipóteses (Figura 1):

- Hipótese 1: os conflitos intragrupais afetam a satisfação no trabalho dos professores.

- Hipótese 2: a satisfação influencia de forma significativa e positiva o engajamento dos professores.

- Hipótese 3: os conflitos intragrupais possuem um efeito moderador da relação entre satisfação e engajamento dos professores no trabalho.

Figura 1. Desenho do modelo teórico de pesquisa

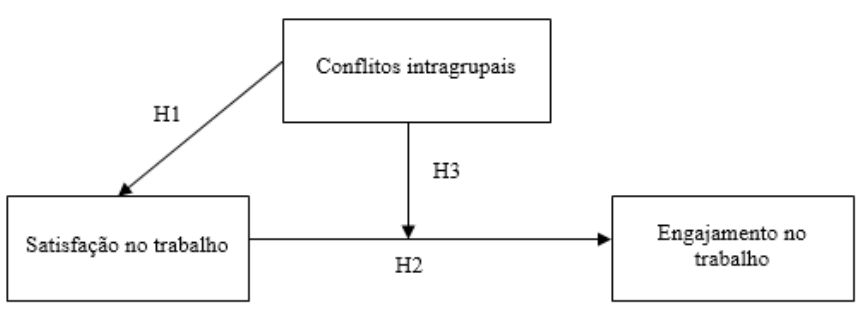

Fonte: Elaborada pelos autores (2017).

\section{Método}

Para consecução dos objetivos propostos, foi realizada uma pesquisa de caráter quantitativo descritiva, denominada estatística inferencial. Os 
estudos descritivos são aqueles que não se detêm necessariamente em explicar e intervir em frente aos fenômenos, mas são estudos que descrevem a realidade (ARAGÃO, 2013). A coleta de dados foi realizada através de uma survey (MALHOTRA, 2012) com o intuito de analisar as seguintes categorias: satisfação no trabalho, conflitos no trabalho e engajamento no trabalho. Os critérios de ambiente social e localização geográfica das escolas não foram considerados porque os estudos analisados na fase exploratória, indicaram que há um expressivo fluxo de estudantes que estudam próximo do local de trabalho, mesmo que distante das suas residências, tornando o público das escolas heterogêneo.

Os dados foram coletados entre os meses de junho e julho de 2016 a partir de questionários estruturados aplicados de forma não probabilística aleatória, observando especialmente o critério de número de professores por escola. Os questionários foram aplicados pelos pesquisadores nas escolas durante os períodos de formação docentes. O tempo médio de preenchimento do instrumento foi de sete minutos.

Para medir as percepções dos professores, foi aplicado um instrumento dividido em quatro partes. A primeira parte destinava-se ao mapeamento de aspectos sociodemográficos; a segunda parte era constituída da versão resumida da EST (SIQUEIRA, 1995), para medir o grau de contentamento do trabalhador frente às dimensões presentes no trabalho. A escala é composta por 15 questões, dividas em cinco dimensões referentes à: satisfação com os colegas; satisfação com o salário; satisfação com a chefia; satisfação com a natureza do trabalho; e satisfação com as promoções. A terceira parte apresentava a ECI (MARTINS; GUIMARÃES; OLIVEIRA, 2006) para avaliar a percepção de conflitos existentes no ambiente de trabalho. A ECI é composta por nove itens, nos quais cinco itens referem-se aos conflitos de relacionamento (itens de 1 a 7 ) e quatro itens referem-se aos conflitos de tarefa (itens de 6 a 9). Os questionários de satisfação e conflito foram utilizados com uma adaptação na escala de respostas, em que se optou por uma escala de tipo Likert de sete pontos, variando de totalmente insatisfeito até totalmente satisfeito para EST, e de nenhum até muitíssimo para ECI. Por fim, a EEGT (SIQUEIRA et al., 2011) buscou aferir o grau de engajamento no trabalho, por meio de duas dimensões: vigor e absorção. Tais dimensões representam o conceito de engajamento no trabalho, que foi definido como um estado mental positivo, assentado em crenças a respeito da intensidade com que o indivíduo se sente vigoroso e absorvido enquanto realiza suas atividades profissionais. A EEGT é constituída por 10 itens, sendo que cinco itens representam a dimensão vigor e cinco itens representam a dimensão absorção. Os itens são respondidos em uma escala do tipo Likert de sete pontos variando de nunca até sempre.

Os dados foram analisados no Software Package for Statistical Analysis (SPSS). Para determinação da confiabilidade das escalas, foi utilizado o Alfa de Cronbach $(\alpha)$ e, para avaliação da normalidade da distribuição dos dados, o teste Kolmogorov-Smirnov (K-S). Em seguida, foi realizada a análise descritiva com a verificação das médias das variáveis do estudo. Por fim, foi realizada uma análise de regressão linear para testar a relação entre as variáveis e uma proposta de moderação para avaliar o efeito dos conflitos na relação entre satisfação e engajamento no trabalho. Todas as análises observaram a capacidade explicativa do modelo $\left(\mathrm{r}^{2}\right)$, o coeficiente de variação $(\beta)$ e a significância estatística de 5\% $(\mathrm{p}<0,05)$, permitindo um índice de confiança de $95 \%$.

\section{Apresentação e discussão dos resultados}

Em relação às características sociais, a amostra foi composta por $82,6 \%$ de mulheres e $17,4 \%$ de homens, sendo que $10 \%$ da amostra tem entre 18 e 30 anos; $25,9 \%$, entre 31 e 40 anos; $36,3 \%$, entre 41 e 50 anos; e $27,9 \%$, com mais de 51 anos, demostrando que a maioria dos respondentes foram mulheres com mais de 41 anos. Dentre os participantes, há professores que atuam há mais de 10 anos na escola (43,8\%); mantém outro emprego paralelo à atividade docente (51\%); e a dedicação em número de horas está presente de forma expressiva em dois grupos: até 20 horas $(45,8 \%)$ e 40 horas $(40 \%)$.

$\mathrm{Na}$ avaliação da confiabilidade das escalas com a utilização do Alfa de Cronbach, o escore geral encontrado para EST foi de 0,866, ficando acima do índice de validação da escala no estudo de Siqueira (1995). A confiabilidade também foi verificada nas dimensões da escala: satisfação com colegas $(0,794)$, satisfação com o salário $(0,872)$, satisfação com a chefia $(0,872)$, satisfação com a natureza do trabalho $(0,675)$ e satisfação com as promoções $(0,627)$. Na ECI, o índice de confiabilidade foi de 0,934 , superior ao escore encontrado no teste de validação do instrumento no 
estudo de Martins, Guimarães e Oliveira (2006). No escore levantado a partir das dimensões da escala foi constatado um Alfa de Cronbach de 0,934 para conflito de relacionamento e, de 0,885 para conflito de tarefa. Por último, foi verificada a confiabilidade da EEGT que também se mostrou com números satisfatórios de confiabilidade nas dimensões vigor $(0,848)$ e absorção $(0,711)$.

A terceira etapa da análise dos dados foi a avaliação das médias encontradas em cada uma das escalas. Para isso, fez-se uso da estatística descritiva para evidenciar as médias de cada uma das variáveis do estudo. Com relação à ECI, os dados mostraram que todas as médias ficaram abaixo dos índices considerados necessários para caracterização de conflitos. $\mathrm{Na}$ dimensão conflito por tarefas, a média foi de 3,85 e no conflito afetivo, a média foi de 3,52, ficando abaixo do valor de 4,5 predito na escala validada por Martins, Guimarães e Oliveira (2006).

Através da análise das médias da EST foi possível verificar um índice de insatisfação nas questões relacionadas à remuneração e oportunidade de ascensão profissional na carreira, como mostram as médias dos itens: número de promoções na carreira $(3,05)$; salário comparado ao trabalho (2,77); salário comparado à capacidade profissional $(2,67)$; oportunidade de ser promovido na carreira $(3,01)$; e salário comparado com o esforço $(2,82)$. No entanto, nos itens restantes da escala foram atribuídas notas que indicam um alto índice de satisfação e, por consequência, elevaram as médias atribuídas aos itens nos quais os professores consideram-se satisfeitos, obtendo-se, assim, um índice relevante de satisfação com o trabalho na média geral.

O cruzamento das informações sociográficas sobre a EST mostrou a relação entre tempo de atuação na escola com a satisfação no trabalho. Os respondentes do grupo 2 (entre 1 e 5 anos) e grupo 4 (mais de 10 anos) de atuação na escola mostraram escores de satisfação abaixo da média: 4,22 e 4,09, respectivamente. A análise de frequência mostrou que os professores nesses grupos totalizaram $70,4 \%$ da amostra, o que atribui ao dado um destaque especial. A média dos respondentes no grupo 1 (com menos de um ano) e grupo 3 (de 6 a 10 anos) ficou levemente acima do mínimo predito na escala $(4,5)$, sendo que no primeiro grupo, a média foi de 4,52, enquanto no terceiro grupo, foi de 4,23.

O resultado da alta satisfação do grupo 1 pode ser entendida pelo pouco tempo de atuação na escola, visto que são pessoas que atuam há menos de um ano na escola pesquisada. Em contrapartida, esses resultados contradizem, em parte, os achados de Pedro e Peixoto (2006) que relataram que os professores que atuam na docência, por aproximadamente 7 a 15 anos, apresentam maior satisfação geral com a profissão. $\mathrm{Na}$ presente pesquisa, os participantes apresentam baixas médias de satisfação quando estão há mais de 10 anos atuando na escola; enquanto que os respondentes que atuam de seis a dez anos na escola, tiveram uma média de satisfação alta.

Os resultados sobre satisfação no trabalho demonstraram que apesar da insatisfação referente ao salário, os professores sentem-se satisfeitos com a profissão, em geral. Este achado mostra que a satisfação vai além de o aspecto financeiro, pois ela também engloba a satisfação com os colegas, chefia, natureza do trabalho e promoções (MURAD;ZAYED; MUKUL, 2013). Em sua maioria, os professores estão satisfeitos com a escolha profissional em função de fatores pessoais, enquanto que a insatisfação está relacionada, muitas vezes, com o papel da instituição no desenvolvimento de suas atividades, bem como, a insatisfação com a estrutura do sistema educacional e o desprestígio da profissão (BUENO; LAPO, 2003; CARDOSO; COSTA, 2016).

Referente ao engajamento no trabalho, as médias variam entre 5,86 e 4,77, indicando um alto nível de engajamento dos pesquisados. As afirmativas com menor média estão relacionadas ao revigoramento no trabalho $(4,77)$ e ao distanciamento dos problemas pessoais $(4,84)$. As maiores médias estão relacionadas ao foco no que o professor está fazendo $(5,86)$ e à disposição para o trabalho $(5,55)$. Com as médias altas, estes dados sugerem que os professores sentem-se bem ao realizar as tarefas do trabalho, demonstrando estarem dispostos, fortalecidos, renovados, concentrados, mantendo o foco e a energia, corroborando com o estudo de Caldas et al. (2013).

Após essa análise descritiva, realizou-se a verificação dos dados com a aplicação de uma análise de regressão linear para o teste das hipóteses. Em relação à hipótese 1 (de que os conflitos intragrupais afetam a satisfação no trabalho), a análise comprovou que, embora a capacidade explicativa do modelo seja baixa $(8,6 \%)$, a relação entre conflitos intragrupais e satisfação com o trabalho é significativa, com destaque para a influência dos conflitos por relacionamento na satisfação com o trabalho (Tabela 1). 
Tabela 1. Influência dos conflitos na satisfação no trabalho

\begin{tabular}{|c|c|c|c|c|c|}
\hline \multicolumn{6}{|c|}{ Coeficientes } \\
\hline \multirow{2}{*}{ Modelo } & \multicolumn{2}{|c|}{ Coeficientes não padronizados } & $\begin{array}{l}\text { Coeficientes } \\
\text { padronizados }\end{array}$ & \multirow[t]{2}{*}{$\mathrm{T}$} & \multirow{2}{*}{ Significância } \\
\hline & B & Erro padrão & Beta & & \\
\hline (Constante) & 4,880 & 0,193 & & 25,316 & 0,000 \\
\hline $\begin{array}{l}\text { Conflitos por } \\
\text { relacionamento }\end{array}$ &,- 252 & 0,073 &,- 373 & $-3,455$ & 0,001 \\
\hline Conflitos por tarefas & 0,064 & 0,077 & 0,089 & 0,825 & 0,411 \\
\hline
\end{tabular}

a. Variável Dependente: Satisfação no Trabalho

Fonte: Elaborada pelos autores (2017).

Esses resultados mostram a importância de se entender os conflitos de relacionamento nas organizações, visto que eles têm origem em preferências individuais e valores pessoais e contribuem significativamente para o declínio da satisfação no trabalho e prejudicam o grupo no que se refere às questões afetivas, gerando consequências negativas em torno da tarefa a ser realizada. Estes resultados estão alinhados aos achados de Martins; Guimarães; Oliveira (2006) de que os conflitos têm origem nos valores e crenças individuais, mas que podem influenciar no desempenho das tarefas e dificultar o relacionamento entre colegas. Também vai ao encontro das conclusões de Nascimento; Simões (2011) e de Farias et al (2015) sobre a incidência do bom relacionamento entre colegas na satisfação do trabalho e de Capistrano e Cirotto (2014) que associam a satisfação com o bom relacionamento no ambiente pedagógico.

Apesar de as médias de conflitos encontradas serem baixas, um dos objetivos deste estudo foi verificar se existe influência destes conflitos na satisfação e no engajamento no trabalho. Esta estratégia segue a proposição de Carraro e Dos Santos (2011) e Guerreiro et al. (2016), para os quais na prática profissional dos professores é comum que se observem descontentamentos diante dos problemas e dificuldades vivenciados no cotidiano pedagógico.

Ao constatar a relação significativa e positiva entre os constructos conflitos intragrupais e satisfação no trabalho, passou-se para o teste da hipótese 2 (influência da satisfação no engajamento). A análise mostrou uma satisfatória capacidade explicativa do modelo $(\mathrm{r}=27 \%$ ). Isso significa que a satisfação no trabalho afeta de maneira significativa e positiva o engajamento dos professores pesquisados (Tabela 2).

Tabela 2. Influência da satisfação no trabalho no engajamento dos professores

\begin{tabular}{|c|c|c|c|c|c|}
\hline \multicolumn{6}{|c|}{ Coeficientes } \\
\hline \multirow[t]{2}{*}{ Modelo } & \multicolumn{2}{|c|}{$\begin{array}{l}\text { Coeficientes não } \\
\text { padronizados }\end{array}$} & \multirow{2}{*}{$\begin{array}{c}\begin{array}{c}\text { Coeficientes } \\
\text { padronizados }\end{array} \\
\text { Beta }\end{array}$} & \multirow[t]{2}{*}{$\mathbf{T}$} & \multirow[t]{2}{*}{ Significância } \\
\hline & $\mathrm{B}$ & Erro Padrão & & & \\
\hline (Constante) & 2,897 & ,333 & & 8,688 & ,000 \\
\hline Satisfação com os colegas &,- 016 & 0,063 &,- 019 &,- 257 & ,798 \\
\hline Satisfação com salário & 0,003 & 0,053 & 0,005 & 0,060 & 0,952 \\
\hline Satisfação com a chefia & 0,037 & 0,063 & 0,049 & 0,598 & 0,551 \\
\hline $\begin{array}{l}\text { Satisfação com a natureza do } \\
\text { trabalho }\end{array}$ & 0,405 & 0,071 & 0,433 & 5,698 & 0,000 \\
\hline Satisfação com a promoção & 0,099 & 0,066 & 0,131 & 1,495 & 0,136 \\
\hline
\end{tabular}

a. Variável Dependente: Engajamento no Trabalho

Fonte: Elaborada pelos autores (2017). 
Considerando os fatores do constructo satisfação no trabalho, a análise de regressão evidencia que o engajamento está fortemente relacionado com a natureza do trabalho para os professores pesquisados. Estes resultados vão ao encontro das conclusões de Moreira (2010) e Capistrano e Cirotto, 2014) que relacionam a satisfação no trabalho com a identificação com as atividades pedagógicas, autonomia para planejar as aulas, transmissão de conhecimento para os alunos, desafio intelectual no desenvolvimento das tarefas e, muitas vezes, ao avaliar e discutir com os colegas de trabalho sobre o progresso dos alunos nas disciplinas.

Estes resultados vão ao encontro das pesquisas realizadas por Siqueira (2008), Melo, Barbosa e Souza (2011) e Janke, Nitsche e Dickhäuser (2015) ao identificarem que as experiências prazerosas no trabalho resultam em satisfação, levando os trabalhadores a sentirem-se mais engajados nas tarefas, obtendo melhores resultados em termos de criatividade, autonomia e comprometimento. O presente estudo mostrou que os professores estão satisfeitos, em geral, com a profissão levando a um melhor comprometimento na execução de tarefas.

Esta conclusão está na mesma direção dos resultados de Guerreiro et al (2016) que confirmaram a relação entre conflitos e diminuição do engajamento, e de Guimarães e Martins (2008) que relacionaram os conflitos intragrupais com o comprometimento organizacional. Embora a temática do comprometimento não tinha sido proposta por este estudo, a análise do engajamento, pelas suas características próximas à noção de comprometimento, pode auxiliar na interpretação das diferentes influências da qualidade dos relacionamentos interpessoais no envolvimento dos trabalhadores com as atividades laborais.

Em seguida, considerando que as duas primeiras hipóteses foram confirmadas, foi realizada uma análise de moderação para avaliar a relação entre satisfação no trabalho e engajamento, moderado pelos conflitos (hipótese 3). Conforme proposto por Baron e Kenny (1986), uma variável moderadora é entendida como uma variável qualitativa ou quantitativa que afeta a direção e/ou força da relação entre uma variável independente e uma variável dependente. Esta técnica de análise é amplamente utilizada em estudos internacionais na área da Psicologia Organizacional (ABRAHAMS; ALF JR., 1972; BARON; KENNY, 1986; JAMES; BRETT, 1984; PAUL; DICK, 1993).
Hayes e Matthes (2009) e Preacher, Rucker e Hayes (2007) sugeriram um modelo gráfico de moderação para identificação da região da significância, construída a partir dos betas não padronizados e dos intervalos de confiança superior e inferior. Esta técnica foi aplicada para testar a hipótese 3 deste estudo, considerando que os conflitos intragrupais são os moderadores da relação entre a satisfação no trabalho (variável independente) e o engajamento (variável dependente). A região de significância da moderação foi 6,016 ( $\beta$ - 0,0104 e $\mathrm{t}=-1,972, \mathrm{p}<0,052)$ evidenciando que $\mathrm{o}$ efeito moderador existe e influencia a relação (Figura 2). Os resultados mostraram que os professores com maior engajamento tendem a não perceber a relação entre conflitos e satisfação no trabalho. Para tanto, os conflitos intragrupais moderam de maneira significativa e negativa a relação entre satisfação e engajamento.

Figura 2. Efeito moderador dos conflitos na relação entre satisfação e engajamento no trabalho

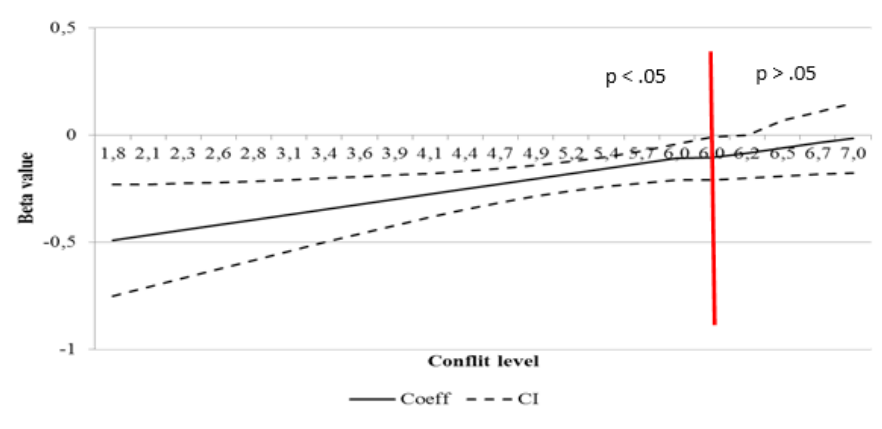

Fonte: Elaborada pelos autores (2017).

Assim, a satisfação com a natureza do trabalho está diretamente relacionada com o engajamento e esta relação é moderada pela percepção de conflitos intragrupais. Isto significa que, a relação entre satisfação com a natureza do trabalho e o engajamento no trabalho, sofre influência da percepção de conflitos para os docentes, com percepções médias e altas de conflitos (até 6,016). Como os resultados da presente pesquisa mostraram que esta variação é negativa, os dados sugerem que os conflitos são importantes vetores do engajamento. Por isto, acredita-se que a confirmação da hipótese 3 traz avanços na discussão teórica sobre a variação do comportamento de influência entre os fatores do engajamento, satisfação e conflitos no ambiente escolar, especialmente por evidenciar a importância dos relacionamento interpessoais para moderação da relação entre satisfação e engajamento. 
Esse resultado, também, enfatiza a necessidade de promover vivências positivas nas atividades laborais dos professores em escolas, diminuindo o risco de conflitos, para aumentar a percepção de satisfação no trabalho (DEJOURS, 2004). Isso corrobora com o estudo de Janke, Nitsche e Dickhäuser (2015), no qual os professores satisfeitos com o trabalho são os que realizam suas atividades com autonomia, criatividade e desenvolvem suas competências. Assim, ter um bom relacionamento com os colegas de trabalho e profissionais da área da educação também é um fator importante para a percepção de satisfação e na diminuição de ocorrências de conflito (JANKE; NITSCHE; DICKHÄUSER, 2015).

Por todo exposto, os resultados da presente pesquisa contribuem com as escolas - e organizações, de modo geral - para atentarem no desenvolvimento de suas políticas e práticas de gestão de pessoas a fim de contribuírem para o desenvolvimento do trabalho de maneira que satisfaça a organização e os seus empregados. No caso, a pesquisa traz resultados que apontam a importância da identificação do sujeito com o seu trabalho; de proporcionar atividades e tarefas que influenciem na disposição e concentração dos empregados; da satisfação com os pares e chefes; da insatisfação com o papel da empresa; de resolver conflitos por relacionamentos; de dar autonomia e desafio intelectual para os empregados; e de propiciar a troca de conhecimento entre os colegas de trabalho. Esses achados contribuem para que as atividades organizacionais sejam realizadas de maneira que propicie a empresa obter resultados diferenciais no mercado de atuação, visto o engajamento, comprometimento e satisfação dos seus empregados.

\section{Considerações finais}

O objetivo deste estudo foi analisar a relação entre conflitos, engajamento e satisfação no trabalho para professores da rede pública de Ensino Médio. Os dados mostraram que em relação aos conflitos, os professores tendem a ter um bom convívio entre colegas, especialmente pela ausência de divergências acentuadas sobre o desenvolvimento das tarefas entre os professores. No que se refere às variáveis do estudo, ainda que os professores não tenham manifestado a existência de conflitos em níveis elevados, os conflitos afetivos influenciam positivamente a autopercepção de satisfação no trabalho, comprovando a hipótese da correlação entre as duas variáveis da pesquisa.
Referente ao engajamento no trabalho, os dados sugerem um alto nível de engajamento, visto que os professores sentem-se bem ao realizar as tarefas do trabalho e sentem-se revigorados, dispostos e focados no trabalho. Os dados também evidenciaram que a satisfação afeta o engajamento, comprovando a hipótese 2.

Por fim, a análise de moderação evidenciou que os conflitos moderam a relação entre satisfação e engajamento. Foi observado que professores que percebem níveis maiores de conflito tendem a ver o seu trabalho como menos satisfatório e sentem-se menos engajados, principalmente na natureza do trabalho. Contudo, percebe-se uma limitação na exploração dos conflitos, já que estes podem proporcionar sensações diferentes dentro das organizações. Por ser considerado um conceito multidimensional, a existência de conflitos pode tanto estimular a criação de ambientes mais produtivos (dimensão racional), como criar prejuízo, destruindo valores e causando sofrimento aos envolvidos (dimensão emocional) (DIMAS; LOURENÇO; MIGUÉZ, 2007).

Desta forma, ao relacionar três constructos multidimensionais, tanto na sua influência direta, quanto na sua moderação, este estudo incorpora a complexidade inerente a estes conceitos para aprofundar a análise acerca dos aspectos subjetivos e organizacionais que afetam o trabalho dos professores de ensino médio da rede pública. Reitera-se que embora a análise descritiva da amostra tenha apresentado bons níveis de satisfação e engajamento no trabalho, associados à um baixo nível de conflito, a relação de influência entre os constructos foi confirmada, o que sugere uma atenção especial aos elementos subjetivos que estes trabalhadores mobilizam na sua prática pedagógica e laboral.

Para estudos futuros, sugere-se que esta pesquisa seja ampliada considerando as variáveis sociográficas e as questões relacionadas à carga horária de trabalho, pois a grande maioria dos professores mantém outro vínculo de trabalho paralelo ou atuam em mais de uma escola. Sugere-se, também, aprofundar os níveis de conflito e percepções de engajamento (vigor e absorção), através de estudos qualitativos. Por fim, visto a diferença de resultados da presente pesquisa com a de Pedro e Peixoto (2006) em relação aos professores com diferentes tempos de trabalho na escola, é oportuno analisar os conflitos intragrupais e a satisfação no trabalho para os trabalhadores que recém foram contratados e aqueles que estão há mais de 10 e/ou 20 anos na organização. 
Com base no exposto, a pesquisa cumpriu com o seu objetivo, trazendo insights importantes sobre o mundo do trabalho dos professores da rede pública do ensino médio, manifestando que o ambiente escolar é um importante local de trabalho. A arte de ensinar requer esforço tanto psicológico quanto físico, uma vez que, muitas vezes, os professores enfrentam situações adversas nas atividades laborais, como ensinar alunos com comportamento difícil, cumprir com as expectativas dos pais dos alunos e equilibrar a jornada de trabalho com a vida pessoal.

Assim, discutindo os principais pontos que influenciam para a satisfação com o trabalho e no engajamento nas atividades laborais dos professores, bem como o mapeamento da existência de conflitos organizacionais, pode-se ver as principais necessidades psicológicas desses trabalhadores que devem ser ajustadas no ambiente escolar. Conforme a psicologia das organizações (BENDASSOLLI, 2012; DEJOURS, 2004), compreender como as pessoas vivem no seu trabalho é fundamental, pois o trabalho é um agente para construção da saúde e na realização de si. Por outro lado, se a organização não entende os anseios dos seus empregados, pode-se gerar um trabalho patogênico.

O desafio dos gestores atual é promover ambientes de trabalho saudáveis e harmoniosos, atendendo as necessidades subjetivas de cada sujeito e, principalmente, preservando a natureza do trabalho docente. Uma possibilidade é criar políticas de formação continuada a professores e programas para ampliar com profundidade a visão do professor sobre suas carências, desafios e as limitações enfrentadas no ambiente escolar.

\section{Referências Bỉbliográficas}

ABRAHAMS, N. M.; ALF JR., E. Pratfalls in moderator research. Journal of Applied Psychology, Washington, v. 56, n. 2, p. 245-251, 1972.

AGAPITO, P. R.; FILHO, A. P.; SIQUEIRA, M. M.

M. Bem-Estar no trabalho e percepção de sucesso na carreira como antecedentes de intenção de rotatividade. Revista de Administração Mackenzie, v. 16, n. 6, 2015.

ARAGÃO, J. Introdução aos estudos quantitativos utilizados em pesquisas científicas. Revista práxis, v. 3, n. 6, 2013.
BARON, R. M.; KENNY, D. A. The moderatormediator variable distinction in social psychological research: conceptual, strategic, and statistical considerations. Journal of Personality and Social Psychology, v. 51, n. 6, p. 1173-1182, 1986.

BAKKER, A. B.; DEMEROUTI, E. Towards a model of work engagement. Career development international, v. 13, n. 3, p. 209-223, 2008.

BAKKER, A. B.; DEMEROUTI, E.; LIEKE, L. Work engagement, performance, and active learning: The role of conscientiousness. Journal of Vocational Behavior, v. 80, n. 2, p. 555-564, 2012.

BAKKER, A. B.; LEITER, M. P. Where to go from here: integration and future research on work engagement. In A. B., Bakker, M. P. Leiter (Orgs.), Work Engagement: a handbook of essential theory and research (p. 181-196). New York: Psychology Press, 2010.

BENDASSOLLI, P. F. Reconhecimento no trabalho: perspectivas e questões contemporâneas. Psicologia em Estudo, v. 17, n 1, p. 37-46, 2012.

CALDAS, C. B.; SOMENSARI, P.; DA COSTA, S. N.; SIQUEIRA, M. M. M.; DOS SANTOS CLARO, J. A. C. Satisfação e engajamento no trabalho: docentes temáticos e auxiliares da EAD de universidade privada brasileira. Gerais: Revista Interinstitucional de Psicologia, v. 6, n. 2, p. 225-237, 2013.

BUENO, B. O.; LAPO, F. R. Professores, desencanto com a profissão e abandono do magistério. Cadernos de pesquisa, v. 118, p. 65-88, 2003.

CAPISTRANO, D.; CIROTTO, A. C. O que Torna o Professor Brasileiro Satisfeito com Sua Profissão? Education Policy Analysis Archives, v. 22, 2014.

CARDOSO, C. G.; COSTA, N. M. Fatores de satisfação e insatisfação profissional de docentes de nutrição. Ciência \& Saúde Coletiva, v. 21, n. 8, 2016.

CARRARO, P.; DOS SANTOS, A. A. O professor do ensino fundamental em grupos de reflexão. Revista Mal-estar E Subjetividade, v. 11, n. 4, 2011.

CAVALCANTE, M. M. Engajamento no trabalho, bem-estar no trabalho e capital psicológico: um estudo com profissionais da área de gestão de pessoas. 2013. 60f. Dissertação (Mestrado)- Programa de Pós-Graduação em Administração, Universidade Metodista de São Paulo, São Bernardo do Campo, 2013. 
CESAR, D. R. Satisfação no trabalho do docente de língua inglesa: um estudo exploratório na rede pública estadual de Palmas - TO. 2011. 90f. Dissertação (Mestrado) - Faculdade de Educação, Universidade de Brasília, Brasília, 2010.

COELHO J. F. A.; FAIAD, C. Evidências de validade da Escala de Satisfação no Trabalho. Avaliação

Psicológica, v. 11, n. 1, 2012.

DA SILVA, L. H. B.; DOS SANTOS, I. P. T.; DE SAMPAIO, V. R. Os gestores e os conflitos organizacionais: um estudo em lojas de eletro eletrônico situado na cidade de Pereira BarretoSP. Revista Interatividade, v. 4, n. 2, p. 04-23, 2016.

DE ANDRADE, G. A.; MIRANDA K. Z.; JARDIM, P. D. Carreira tradicional versus carreira autodirigida ou proteana: um estudo comparativo sobre a satisfação com a carreira, a profissão e o trabalho.

Revista de Ciências da Administração, v. 13, n. 31, 2011.

DEJOURS, C. Subjetividade, trabalho e ação. Revista produção, v. 14, n. 3, p. 27-34, 2004.

DIMAS, I. C. D.; LOURENÇO, P. R.; MIGUÉZ, J. (Re) pensar os conflitos intragrupais: desempenho e níveis de desenvolvimento. Psicologia, v. 21, n. 2, 2007.

DO CARMO, J. G. M.; GUIMARÃES, L. de V. M.; CAEIRO, M. Prazer e sofrimento no trabalho: vivências de mulheres soldados da PMMG. FarolRevista de Estudos Organizacionais e Sociedade, v. 3, n. 8, p. 1278-1322, 2017.

FARIAS, G. O.; BOTH, J.; FOLLE, A.; PINTO, M. G.; DO NASCIMENTO, J. V. Satisfação no trabalho de professores de educação física do magistério público municipal de Porto Alegre. Revista Brasileira de Ciência e Movimento, v. 23, n. 3, p. 5-13, 2015.

FRAGA, V. F.. (2007). A postura do professor e as grandes questões humanas nas práticas educacionais. Cadernos EBAPE.BR, 5(spe), 01-14.

GUETZKOW, H.; GYR, J. An analysis of conflict in decision-making groups. Human relations, v. 7, n. 3 , p. 367-382, 1954.

GUERREIRO, N. P.; NUNES, E. F. P. A.; GONZALEZ, A. D.; MESAS, A. E. Perfil Sociodemográfico, Condições E Cargas De Trabalho De Professores Da Rede Estadual De Ensino De
Um Município Da Região Sul Do Brasil. Trabalho, Educação e Saúde, v. 14, p. 197-217, 2016.

GUIMARÃES, V. F. Bases de poder do supervisor, conflitos intragrupais e comprometimento organizacional e com a equipe: um estudo exploratório. 2007. 143f. Dissertação (Mestrado) Faculdade de Psicologia, Universidade Federal de Uberlândia, Uberlândia, MG, 2007.

GUIMARÃES, V. F.; MARTINS, M. do C. F. Bases de poder do supervisor, conflitos intragrupais e comprometimento organizacional e com a equipe. Revista Psicologia Organizações e Trabalho, v. 8, n. 2, p. 54-78, 2008.

HAYES, A. F.; MATTHES, J. Computational procedures for probing interactions in OLS and logistic regression: SPSS and SAS implementations. Behavior research methods, v. 41, n. 3, p. 924-936, 2009.

HAKANEN, J. J.; SCHAUFELI, W. B.; AHOLA, K.; The Job Demands-Resources model: A threeyear cross-lagged study of burnout, depression, commitment, and work engagement. Work e Stress, v. 22, n. 3, p. 224-241, 2008.

JEHN, K. A. Enhancing effectiveness: An investigation of advantages and disadvantages of value-based intragroup conflict. International journal of conflict management, v. 5, n. 3, p. 223238, 1994.

JAMES, L. R.; BRETT, J. M. Mediators, moderators, and tests for mediation. Journal of Applied

Psychology, v. 69, n. 2, p. 307, 1984.

JANKE, S.; NITSCHE, S.; DICKHÄUSER, O.

The role of perceived need satisfaction at work for teachers' work-related learning goal orientation.

Teaching and Teacher Education, v. 47, p. 184-194, 2015.

LOCKE, E. A. What is job satisfaction?

Organizational behavior and human performance, v. 4, n. 4, p. 309-336, 1969.

LOCKE, E. A. The nature and causes of job satisfaction. In: DUNNETTE, M. D. (Ed.). Handbook of industrial and organizational psychology. Chicago: Rand McNally. College Publishing, 1976. p. 1297-1349.

MACHADO, M. C.; SILVESTRE, R. C.; JOSÉ, N. 
K.; JÚNIOR, N. K. Evaluation of job satisfaction of employees of a public hospital care recognized effectiveness. Revista Brasileira de Oftalmologia, v. 73, n. 3, p. 143-147, 2014.

MALHOTRA, N. K. Pesquisa de Marketing. Uma orientação aplicada. Tradução de Lene Belon Ribeiro, Monica Stefani. 6. ed. Porto Alegre: Bookman, 2012.

MARTINEZ, M. C; PARAGUAY, A. I. B. B. Satisfação e saúde no trabalho: aspectos conceituais e metodológicos. Cadernos de psicologia social do trabalho, v. 6, p. 59-78, 2003.

MARTINS, M. do C. F.; SANTOS, G. E. Adaptação e validação de construto da Escala de Satisfação no Trabalho. PsicoUSF, v. 11, n. 2, p. 195-205, 2006.

MARTINS, M. C. F.; GUIMARÃES, V. F.; OLIVEIRA, M. C. Adaptação e validação fatorial da Escala de Conflitos Intragrupais. In: Anais do II Congresso Brasileiro de Psicologia Organizacional e do Trabalho, 2006.

MARTINS, A. C.; TAVARES, A. R. Estudo da relação entre os conflitos intragrupais e a performance acadêmica: Investigação e métodos de análise avançada. 2013. Disponível em internet: < https://www.researchgate.net/profile/ Ana_Martins50/publication/259532377_Estudo_ da_Relacao_entre_os_Conflitos_Intragrupais_e_a_ Performance_Academica_Investigacao_com_ alunos_da_Universidade_da_Beira_Interior/ links/02e7e52c6a0aabcbaa000000/Estudo-daRelacao-entre-os-Conflitos-Intragrupais-e-aPerformance-Academica-Investigacao-com-alunos-daUniversidade-da-Beira-Interior.pdf > . Acesso em 08 set. 2017.

MELO, M. B. de; BARBOSA, M. A.; SOUZA, P. R. de. Job satisfaction of nursing staff: integrative review. Revista latino-americana de enfermagem, v. 19, n. 4, p. 1047-1055, 2011.

MENDES, A. M. Da psicodinâmica à psicopatologia do trabalho. In: MENDES, A. M. Psicodinâmica do trabalho: Teoria, método e pesquisas. São Paulo: Casa do Psicólogo, p. 23-48, 2007 a.

MENDES, A. M. Novas formas de organização do trabalho, ação dos trabalhadores e patologias sociais. In: MENDES, A. M. Psicodinâmica do trabalho: Teoria, método e pesquisas. São Paulo, SP: Casa do Psicólogo, p. 49-87, 2007b.
MOREIRA, H. As dimensões da satisfação e da insatisfação de professores do ensino médio. Revista Brasileira de Ensino de Ciência e Tecnologia, v. 3, n. 2, 2010.

MURAD, M. M. I.; ZAYED, N. M.; MUKUL, A. Z. A. A study on job satisfaction: focus on bankers of Bangladesh. European Journal of Business and Management, v. 5, n. 17, p. 14-20, 2013.

NASCIMENTO, T. A.; SIMÕES, J. M. Análise da gestão de conflitos interpessoais nas organizações públicas de ensino profissionalizante em Nova Iguaçu-RJ. Revista de Gestão, v. 18, n. 4, p. 585-603, 2011.

NEVES, V. F.; OLIVEIRA, Á. de F.; ALVES, P. C. Síndrome de burnout: impacto da satisfação no trabalho e da percepção de suporte organizacional. Psico, v. 45, n. 1, p. 45-54, 2014.

OLIVEIRA, T. F.; DE LINS, V. L.; DA SILVA, R. M.; FONTOURA, R. V. Qualidade de vida no trabalho: um estudo comparativo entre professores de escola pública e privada. Psicologia Argumento, v. 34, n. 85, 2016.

PAUL, L.S.; DICK, A. Using moderator variables in structural equation models. In: McALISTER, L.; ROTHSCHILD, M. L. (Ed.). Advances in consumer research. Provo, UT: Association for Consumer Research, p. 636-640, 1993.

PEDRO, N.; PEIXOTO, F. Satisfação profissional e auto-estima em professores dos $2 .^{\circ}$ e $3{ }^{\circ}{ }^{\circ}$ ciclos do Ensino Básico. Análise Psicológica, v. 24, n. 2, p. 247-262, 2006.

PREACHER, K. J.; RUCKER, D. D.; HAYES, A. F. Addressing moderated mediation hypotheses: Theory, methods, and prescriptions. Multivariate behavioral research, v. 42, n. 1, p. 185- 227, 2007.

RUEDA, F. J.; BAPTISTA, M. N.; DE SOUZA, M. S.; DEGENHARDT, I.; NICOLETTI, I. G. Escala de Suporte Laboral (ESUL) e Escala de Satisfação no Trabalho: evidências de validade. Avaliação Psicológica, v. 9, n. 3, 2010.

ROSSI, E. Z. Método de pesquisa em

Psicodinâmica do Trabalho. Curitiba: Juruá, 2010.

SCHAUFELI, W. B.; BAKKER, A. B. Job demands, job resources, and their relationship with burnout and engagement: a multi-sample study. Journal of 
Organizational Behavior, v. 25, p. 293-315, 2009.

SINOT'T, E.; AFONSO, M. R.; RIBEIRO, J. A. B.; FARIAS, G. Síndrome de Burnout: um estudo com professores de Educação Física. Movimento, v. 20, n. 2, 2014.

SIQUEIRA, M. M. M. Antecedentes de comportamentos de cidadania organizacional: a análise de um modelo pós-cognitivo. 1995. 265f. Tese (Doutorado) - Instituto de Psicologia, Universidade de Brasília, Brasília DF, 1995.

SIQUEIRA, M. M. M.; GOMIDE JR., S. Vínculos do indivíduo com o trabalho e com a organização. In: ZANELLI, J. C.; BORGES-ANDRADE, J. E.; BASTOS A. V. B. (Orgs). Psicologia, organizações e trabalho no Brasil. Porto Alegre: Artmed, p. 300328, 2004.

SIQUEIRA, M. M. M. Proposição e análise de um modelo para comportamentos de cidadania organizacional. Revista de Administração

Contemporânea, v. 7, n. SPE, p. 165-184, 2003.

SIQUEIRA, M. M. M. Esquema mental de reciprocidade e influências sobre afetividade no trabalho. Estudos de Psicologia, v. 10, n. 1, p. 83-93, 2005.

SIQUEIRA, M. M. M. Satisfação no trabalho. In: SIQUEIRA, M. M. M. (Org.). Medidas do Comportamento Organizacional. Porto Alegre: Artmed, p. 265 - 274, 2008.

SIQUEIRA, M. M. M.; MARTINS, M. C. F.; LIMA, L. G.; AGAPITO, P. R.; SOUZA, W. S. Construção e validação fatorial da Escala de Engajamento no Trabalho - EEGT. In: Anais do Congresso LusoBrasileiro de Psicologia da Saúde e Congresso Ibero - Americano de Psicologia da Saúde, 2/1, 2011.

SIQUEIRA, M. M. M; MARTINS, M. F.; ORENGO, V.; SOUZA, W. Engajamento no trabalho. In: SIQUEIRA, M. M. (Org.). Novas medidas do comportamento organizacional: ferramentas de diagnóstico e de gestão. Porto Alegre: Artmed, v. 1, p. 148-155, 2014. 